Hranovska, T. (2013). Rol vykhovatelia u formuvanni ekolohichnoi svidomosti ditei doshkilnoho viku [The role of the teacher in shaping the ecological consciousness of preschool children]. Research Notes. Series "Psychology and Pedagogy Research" (Nizhyn Mykola Gogol State University], 5, 129-132 [in Ukrainian].

Kurniak, L. M. (2015). Ekolohichna kultura: poniattia ta formuvannia [Ecological culture: concepts and formation]. Zbirnyk naukovykh prats Khmelnytskoho instytutu sotsialnykh tekhnolohii Universytetu «Ukraina» [Collection of Scientific Papers of Khmelnytsky Institute of Social Technologies of University "Ukraine"], 10, 48-51 [in Ukrainian].

Lisovska, T. (2016). Problema profesiinoi pidhotovky maibutnikh fakhivtsiv z doshkilnoi osvity u vyshchykh navchalnykh zakladakh [The Problem of Professional Training of Future Specialists in Preschool Education in Higher Educational Institutions]. Naukovyi visnyk MNU imeni V. O. Sukhomlynskoho. Seriia Pedahohichni nauky [Scientific Bulletin of VO Sukhomlinsky National University. Series Pedagogical Sciences], 2(53), 101-108 [in Ukrainian].

Lysenko, N. V. (2009). Teoriia i praktyka ekolohichnoi osvity: doshkilnyk-pedahoh [Theory and practice of environmental education: preschool teacher]. Kyiv: Slovo [in Ukrainian].

Naida, R. H. (2016). Do problemy formuvannia zhyttievoi kompetentnosti dytyny v doshkilnomu zakladi [To the problem of forming the child's vital competence in preschool institution]. Zhytomyr Ivan Franko State University Journal. Pedagogical Sciences, 2(84), 86-90 [in Ukrainian].

Naumenko, T. S. (2012). Psykholoho-pedahohichni mekhanizmy spryimannia avtorskykh kazok pryrodoznavchoho zmistu ditmy starshoho doshkilnoho viku v konteksti ekolohichnoho vykhovannia [Psychological and pedagogical mechanisms of perception of copyright fairy tales of children of older preschool age in the context of ecological education]. Research Notes. Series "Psychology and Pedagogy Research" (Nizhyn Mykola Gogol State University), 5, 117-121 [in Ukrainian].

Vashak, O. (2009). Pidhotovka maibutnikh vykhovateliv do ekolohichnoho vykhovannia doshkilnykiv na zasadakh etnopedahohiky [Preparation of future educators for ecological education of preschool children on the basis of ethnopedagogy]. Pedagogical Sciences, 2, 49-54 [in Ukrainian].

Volkova, V. A., \& Barsuk, S. O. (2017). Pedahohichni umovy ekolohichnoho vykhovannia ditei starshoho doshkilnoho viku [Pedagogical conditions of ecological education of preschool children]. Collection of scientific works "Pedagogical sciences", 2(75), 11-15 [in Ukrainian].

\title{
OLENA HAVRYLO
}

Place of work: Sumy A. S. Makarenko Pedagogical University

Country: Ukraine

Email:leih972@gmail.com

PROBLEMS OF THE PRESCHOOL TEACHERS' AND PARENTS' PREPAREDNESS TO ENJOYMENT OF ENVIRONMENTAL EDUCATION OF PRESCHOOL AGE CHILDREN

The article presents the results of the study of pedagogical readiness of the teachers of pre-school educational institutions to conduct ecological upbringing of children. The first problem is the insufficient definition of entrepreneurship of the ecological culture by the educators. The other side of the problem is their limited knowledge of current developments in the environmental education of preschoolers. And few educators carry out environmental education in the system, combining it with other spheres of knowledge. During the acquaintance of the children with nature attention is paid to their mental and aesthetic development, but the axiological aspect remains aside. A positive trend is the using of methods of direct contact with nature among the tools; literature and art works as well. The preschoolers work at the kindergarten land plot, in the corner of wildlife. Also, natural objects predominate as a means of education. However, during receiving the knowledge children do not always have a well-established nature-based behavior, and educators do not use the opportunity to give a good example of it. Small number of the teachers work with ecological tales and the creativity of children. At the same time, parents rarely continue the process of environmental education at home, motivated by lack of time and methodological knowledge and skills. Children aren't trust care for animals and plants. As a conclusion it is necessary to raise the ecological culture of educators, who should cooperate with the parents of pupils in this area of activity.

Key words: environmental education; ecological culture; preschool education; preschool teachers; pre-school education institution; cooperation with parents.

Одержано 05.09.2019

УДК 374(091)

DOI: https://doi.org/10.33989/2524-2474.2019.74.196621

\section{ВАЛЕНТИНА ДВІЖОНА}

ORCID: 0000-0002-0315-4406

(Київ)

Place of work: Preshov, University

Country: Ukraine

Email:valen.tina79@ukr.net

\section{ОСОБЛИВОСТІ МОТОРНОГО ТА КОГНІТИВНОГО РОЗВИТКУ ДІТЕЙ ДОШКІЛЬНОГО ВІКУ З МОТОРНОЮ АЛАЛІєЮ}

У ході викладу матеріалів статті висвітлену проблему моторного та когнітивного розвитку дітей дошкільного віку з моторною алалією, що набула пріоритетного значення на сучасному етапі розвитку інклюзивної освіти в Україні та світі. Це пов'язано із збільшенням кількості дітей з різноманітними мовленнєвими порушеннями, які впливають на рівень засвоєння дитиною навчального матеріалу. 
У статті детально описано структуру дефекту при алалії, яка характеризується нерівномірністю вербальних і невербальних порушень, що ускладнює розвиток мовлення, які труднощі долають діти з моторною алалією при оволодінні навичками письма, орієнтування в оточуючому просторі. Також у статті робиться акцент на різноманітні порушення самоорганізації, які негативно впливають на процес і результати мислення. I, як висновок, - необхідність орієнтації на індивідуалізацію навчального процесу з урахуванням особливостей моторного та когнітивного розвитку дитини з моторною алалією.

Ключові слова: онтогенез; дизонтогенез; розвиток моторики; когнітивний розвиток; моторна алалія.

Постановка проблеми в загальному вигляді. Серед різноманітних мовленнєвих порушень в дитячому віці найбільшу складність для діагностики та корекційної роботи представляє моторна алалія. Під моторною алалією більшість авторів розуміє системний недорозвиток мовлення, що викликаний пошкодженням мовних зон в домовленнєвому періоді. Так, за визначенням В. Ковшикова, експресивна (моторна алалія) це патологічне засвоєння в онтогенезі одиниць мовлення і особливо - правил його функціонування, що в процесі породження мовлення проявляється в неможливості або неправильності відтворення всіх або частини мовних операцій (семантичних, лексичних, синтаксичних, морфологічних, фонематичних) (Ковшиков, 2006).

Алалія як нозологічна одиниця характеризується порушення всіх компонентів мовлення: семантичного, лексичного, синтаксичного, морфологічного і фонематичного.

Також потрібно брати до уваги той факт, що за останніми даними офіційної статистики відбувається зростання кількості дітей дошкільного віку, що мають ті чи інші порушення мовленнєвого розвитку. Фахівці у галузі корекційної освіти та логопедії фіксують як зміну кількості дітей з мовленнєвими вадами, так і форми патологій розвитку мовлення (гіперактивність, ураження мозку тощо).

Разом з тим механізм алалії на даний час все ще вивчений не в повному обсязі. Представники різних напрямків у вивченні алалії сходяться в тому, що в основі цієї мовної патології лежить органічна недостатність мозку. При цьому одні дослідники дану мовну патологію пов'язують з патологією моторики, інші - з вибірковою недостатністю в оволодінні мовою як своєрідною знаковою системою. На сучасному етапі розвитку логопедії, медицини, логопсихології, нейролінгвістики виникає необхідність уточнення деяких положень, що стосуються патогенезу та структури мовних відхилень при моторній алалії.

Аналіз основних досліджень і публікацій. В багатьох дослідженнях фахівцями в галузі спеціальної педагогіки, логопедії та психології проаналізовано різні аспекти мовленнєвої діяльності дітей 3 мовними патологіями, в тому числі і з алалією.

Так, пізній розвиток експресивного мовлення при алалії відмічають у своїх дослідженнях В. Ковшиков, Р. Левіна, В. Орфінська, О.Усанова.

Р. Бєлова-Давид та Н. Траугот в свої роботах детально описали особливості фонетико-фонематичної сторони мовлення при моторній алалії, яке характеризується порушенням артикуляційної моторики та зниженням слухового контролю за довільним мовленням.

P.Є. Левіна та О. Н. Усанова за результатами своїх досліджень прийшли до висновку про наявність розладів слухового та зорового сприйняття, нестійкості уваги, порушення слухової та зорової пам'яті у дітей 3 тяжкими мовленнєвими патологіями.

В. А. Ковшиков у власних дослідженнях вказує на недоліки керування фонемною системою, які проявляються в пропусках, замінах перестановках звуків.

Авторами відмічається, що структура дефекту при алалії характеризується нерівномірністю вербальних і невербальних порушень, що ускладнює розвиток мовлення. В сучасній літературі підходи щодо подолання алалії з врахуванням психолого-педагогічного та нейропсихологічного аналізу структури дефекту описані в недостатній кількості. Це приводить до розуміння необхідності проведення дослідження щодо встановлення особливостей порушень психомоторного та когнітивного розвитку дітей дошкільного віку з моторною алалією.

Мета статті - на основі медичних, педагогічних вітчизняних та закордонних джерел висвітлити особливості моторного та когнітивного розвитку дітей з моторною алалією.

Виклад основного матеріалу дослідження. Моторна алалія - явище досить неоднорідне, тому існує необхідність її класифікувати.

Так, ряд авторів, виділяють алалію функціональну та органічну. А. Лібман виділяє такі форми алалій: моторна, сенсомоторна, змішані випадки. Р. Левіна класифікує алалію відповідно до порушення: 1) фонематичного слуху; 2) рухової сфери; 3) зорового сприйняття; 4) психічної активності. В. Орфінська наголошує на існуванні трьох форм алалій, які пов'язані з порушеннями: мовно рухового аналізатора, рухового аналізатора, слухового та мовно рухового аналізаторів. У своїх дослідженнях Є. Соботович виділила алалії з переважним порушенням синтагматичних та парадигматичних систем мови дітей з моторною алалією (Соботович, 2003).

Дослідження механізму моторної алалії привели до висновку про наявність порушень в організації і диференціації мовних рухів, тобто основним симптомом порушення артикуляційної моторики при алалії $\epsilon$ апраксія (Трауготт, 1940; Лурия, 1975).

Цікавим є той факт, що ще В. Бєхтєрєв у своїх дослідженнях прийшов до висновку про тісний зв'язок руки і мови. Наявність зв'язку між моторикою пальців та розвитком мовленнєвої функції у свої дослідженнях підтвердили А. Анаткова-Фоміна, М. Кольцова, Є. Ісеніна. В ході цих досліджень було встановлено, що у переважної більшості дітей з недорозвитком мовлення пальці малорухомі, рухи відрізняються неузгодженістю. Це пов'язано з тим, що мовлення, як частина загальної моторики, формується на основі дозрівання 
мовно-рухової функціональної системи. Процеси розвитку мови і моторики тісно взаємопов'язані та залежать багато в чому від функціонування лобних відділень мозку. В межах проведених досліджень обстежувалася психомоторика старших дошкільників 3 недорозвитком мовлення (за допомогою тестів Озерецького), в ході яких було з'ясовано, що виконання дітьми багатьох тестових завдань викликає у них певні труднощі. Були виявлені неточність рухів, труднощі у відтворенні поз руки і пальців, особливо складно дітям було виконати поперемінні та довільні рухи. Чітко прослідковувалися порушення послідовності елементів дій, пропускалися їх складові частини (Бехтерев, 1994; Кольцова, 1973). Аналогічні особливості рухової пам'яті виділили у своїх дослідженнях Г. Чіркіна та Т. Філічева (2004).

Недостатній рівень розвитку моторики зокрема несприятливо позначається на розвитку образотворчих здібностей дітей, проявляючись в труднощах при зображенні простих ліній, виконанні дрібних деталей малюнка, що в подальшому може проявитися труднощами в оволодінні письмом.

Таким чином, специфічні прояви порушень загальної, дрібної та артикуляційної моторики дошкільників з недорозвитком мовлення спостерігаються на всіх рівнях організації рухів.

Що ж стосується психічного розвитку дітей з мовленнєвими патологіями, то він характеризується нерівномірністю когнітивного та мовленнєвого розвитку протягом всього періоду дитинства.

На сучасному етапі розвитку науки, проблемами психічного дизонтогенезу займаються різні фахівці: психіатри, корекційні педагоги, психологи. Багато спеціалістів відмічають поєднання порушень пізнавальної та мовної діяльності у дітей з важкими порушеннями мовлення. Як правило, в них відмічається кореляція між ступенем вираженості патологій мовлення та пізнавальної активності.

Перший системний аналіз особливостей пізнавальних процесів у немовленнєвих дітей з алалією був проведений Р. Левіною. Вона відмічала, що при алалії спостерігається несформованість сенсорних функцій: розлади слухового та зорового сприйняття, ритмічних відчуттів, нестійкість уваги, порушення оптико-просторового праксису, зорової та слухової пам'яті, мислення (Левина, 1977).

Л. Цвєткова в ході своїх досліджень встановила, що зорове сприйняття дошкільників з недорозвитком мовлення відстає в розвитку та характеризується недостатньою сформованістю цілісного образу предмету. Ще одне їі спостереження полягає в тому, що діти даної категорії відрізняються від однолітків 3 нормою розвитку як по об’єму зорового сприйняття предметів так і по стійкості зорових уявлень (Цветкова, 1995).

Є. Мастюкова відмічає, що велика кількість дітей з алалією виявляється не готовою до оволодіння навичками письма, має труднощі в диференціації понять «праворуч», «ліворуч», складнощі виділення структурних елементів, дрібних деталей, спостерігаються труднощі орієнтування у власному тілі, оточуючому просторі, спостерігається знижена швидкість виконання перцептивних операцій орієнтовно-дослідницької діяльності (Мастюкова,1997).

Для дошкільників з недорозвитком мовлення характерною рисою $є$ низький рівень розвитку основних властивостей уваги. Відмічається недостатня його стійкість, періодичні коливання, обмежені можливості розподілення. У дітей з дефіцитом уваги є складнощі з відновленням порядку розташування предметів після їх перестановки, вони не помічають неточностей в малюнках, не завжди виділяють предмети або слова за заданою ознакою. Очевидною $є$ недостатня цілеспрямованість діяльності, її імпульсивність або інертність. Також була виявлена схильність до репродуктивного типу діяльності, несформованість всіх видів контролю, особливо упереджуючого та поточного. Внаслідок цього в дітей виникають значні труднощі при виконанні завдань шкільної програми, вони не можуть сприймати інформацію в повному обсязі без наглядної підтримки (Гаркуша, 1983).

Спостерігаються різноманітні і не завжди пов'язані з органічними ураженнями головного мозку порушення пам'яті. Вираженість порушень пам'яті у дітей з алалією, корелюється з тяжкістю та характером органічних порушень (Мастюкова, 1997). Крім того, було встановлено залежність вербальної пам'яті від ступеня та характеру мовленнєвої патології. Дефіцит короткочасної пам'яті описується закордонними авторами. Вони відмічають її порушення при перевтомі, невротичних станах, загальній астенізації в результаті перенесених інфекцій. Вчені дійшли висновку, що діти з недорозвитком мовлення мають знижений об'єм зорової та тактильної пам'яті, погано сприймають мовні ритми, важко сприймають зорово-просторові співвідношення, мають труднощі з розпізнаванням накладених і вписаних одне в одне зображень. У всіх обстежених дітей виявлено недостатність оптико-просторового гнозису. У дітей з алалією об'єм словесної пам'яті значно нижчий об'єму зорової. Дошкільники часто забувають складні інструкції, пропускають деякі їх елементи, міняють послідовність запропонованих завдань, повільніше орієнтуються в умовах задачі. Діти краще запам'ятовують емоційно яскраві враження на мимовільному рівні, також переважає механічна наглядно-образна пам'ять (Canon, 2006).

Що стосується взаємозв'язку стану мислення та рівня мовленнєвого розвитку, то тут існують суперечливі думки. Відповідно до найбільш розповсюдженої точки зору, обгрунтованої Р. Левіною та іншими вченими (Б. Гріншпун, С. Шаховською), в структурі інтелектуальної недостатності в дітей з тяжкими мовленнєвими патологіями виділяється вторинний недорозвиток мислення (Гриншпун, 1988; Шаховская, 1997). В роботах дитячих психіатрів досліджуються питання взаємозв'язку між мовленнєвою патологією та загальним психічним розвитком дитини, що теж підтверджує дане припущення (Масюкова, 1997; Белова-Давид, 1973).

Ряд авторів встановили специфічні особливості мислення даної категорії дошкільників. Незважаючи на наявність в цих дітей передумов для оволодіння аналітичними операціями, діти відстають в розвитку словесно-логічного мислення, виникають значні труднощі при оволодінні операціями аналізу, синтезу, порівняння та узагальнення (Корнев, 2006; Усанова, 1982). 
У дітей з моторною алалією відмічаються також особливості просторового мислення, діти набагато більше часу, ніж однолітки з нормою розвитку, витрачають на виконання завдань, пов'язаних з обертанням предметів. У них спостерігається дефіцит слухової обробки інформації, порядкової лічби, затримка в оволодінні кількісними операціями (Canon, 2006).

Аналізуючи особливості розвитку дітей з моторною алалією, Є. Соботович приходить до висновку, що в структурі дефекту домінує сповільнення темпу формування психічних процесів. Для дітей $з$ цією мовленнєвою патологією характерною $є$ недостатня гнучкість та динамічність мислення, більш уповільнений темп засвоєння закономірностей (Соботович, 2003).

Дослідження, проведені В. Ковшиковим та Ю. Елькіним вказали на наявність у дітей з моторною алалією різноманітних порушень самоорганізації, які також негативно впливали на процес і результати мислення. Ці порушення переважно охоплювали емоційно-вольову та мотиваційну сфери та найчастіше проявлялися в психофізичній розгальмованості, рідше - в загальмованості, а також у відсутності інтересу до завдань. Діти тривалий час не включалися в проблемну ситуацію, або навпаки, дуже швидко приступали до її виконання, при цьому оцінювали ситуацію поверхнево, не вникаючи в її суть, при виконанні часто відволікалися. Велика кількість дітей під час експерименту відмовлялася працювати через відсутність цікавості до завдання. Коли ж експериментатор впорядковував поведінку дітей, відповідно створюючи психологічні умови для протікання процесу мислення, вони переважно вирішували проблемні ситуації. Отже, можна стверджувати, що на процес і результати мислення впливає недостатність самоорганізації психічної діяльності (Ковшиков, \& Элькин, 1980).

Таким чином, в питанні побудови навчального процесу для дітей з моторною алалією, слід дотримуватися певних алгоритмів: її слід розпочинати з формування психологічних передумов для розвитку мовленнєвої діяльності, розвитку загальної і мовленнєвої моторики, формування ігрової діяльності, корекції зорового, слухового, тактильного сприйняття.

Починаючи роботу з дитиною з моторною алалією, педагог повинен з'ясувати, чим вона цікавиться, до чого має хист, визначити «сильні» сторони дитини. Необхідно поспостерігати, чи намагається дитина говорити, які умови гальмують, а які стимулюють мовлення. Тільки після здійснення педагогічної діагностики можна приступати до системної роботи.

Тобто мова йде про індивідуалізацію та диференціацію навчального процесу. Ще Л. Виготським були розроблені методологічні принципи організації індивідуалізованої корекційно-педагогічної допомоги дітям з особливостями розвитку. Розв'язуючи цю проблему, вчений орієнтувався на особистість дитини з врахуванням її минулого досвіду, її особливостей та перспектив. Описуючи механізм навчання, Л. Виготський виділяв особливою умовою дотримання оптимальної дистанції між вимогами до дитини та її актуальним рівнем інтелекту, зоною її найближчого розвитку. Це є, на думку вченого, визначальною психологічною детермінантою побудови навчального процесу, орієнтованого на розвиток дитини (Выготський, 1999).

\section{Висновки з даного дослідження і перспективи подальших розвідок.}

Одним з головних напрямків розвитку сучасної освіти є напрямок, орієнтований на індивідуалізацію навчання з урахуванням особливостей розвитку кожної дитини. При цьому особливу увагу потрібно приділяти дітям, які потребують додаткового корекційно-педагогічного впливу, особливо враховуючи той факт, що кількість дітей з мовленнєвими патологіями щороку зростає.

Наразі в спеціальній літературі представлено досить небагато підходів по подоланню моторної алалії з урахуванням клінічного та психолого-педагогічного аналізу структури дефекту. В процесі визначення напрямків і змісту корекційної та логопедичної роботи також не завжди враховується варіативність моторних та когнітивних порушень. Це приводить до розуміння необхідності продовжувати наукові дослідження з означеної проблеми.

\section{СПИСОК ВИКОРИСТАНОЇ ЛІТЕРАТУРИ}

Белова-Давид Р. А. Клинические особенности детей дошкольного возраста с тяжелыми формами недоразвития речи : автореф. дис. ... мед. наук. Москва, 1973. 16 с.

Бехтерев В. М. Избранные работы по социальной психологии. Москва : Наука, 1994. 398 с.

Выготский Л. С. Педагогическая психология. Москва : Педагогика-Пресс, 1999. 536 с.

Гаркуша Ю.Ф. Опыт развития произвольного внимания у детей с моторной алалией. Дефектология. 1983. № 4. С. $23-24$.

Гриншпун Б. М. Развитие коммуникативных умений у дошкольников в процессе логопедической работы над связной речью. Дефектология. 1988. № 3. С. 81-84.

Ковшиков В. А. Экспрессивная алалия и методы ее преодоления. Санкт-Петербург : Каро, 2006. 304 с.

Ковшиков В. А., Элькин Ю. А. К вопросу мышления у детей с моторной алалией. Дефектология. 1980. № 2. С. 14-22.

Кольцова М. М. Двигательная активность и развитие функций мозга ребенка: роль двигательного анализатора в формировании высшей нервной деятельности ребенка. Москва : Педагогика. 1973.143с.

Корнев А. Н. Основы логопатологии детского возраста: клинические и психологические аспекты. Санкт-Петербург : Речь. 2006. 380 с.

Левина Р.Е. Свойства личности и овладение речью в норме и патологии. Москва : Академия, 1977.218 с.

Лурия А. Р. Речь и мышление: материалы к курсу лекций по общей психологии. Москва : МГУ. 1975. 120 с.

Мастюкова Е.М. Лечебная педагогика (ранний и дошкольный возраст): советы педагогам и родителям по подготовке к обучению детей с особыми проблемами в развитии. Москва : Владос, 1997. 304 с.

Орфинская В. К. Принципы построения дифференцированной методики обучения алаликов на основании лингвистической классификации форм алалии. Логопедия. Москва : Владос, 2003. 280 с.

Соботович Е.Ф. Речевое недоразвитие у детей и пути его коррекции (дети с нарушением интеллекта и моторной алалией). Москва : Классик стиль, 2003. 160 с. 
Трауготт Н. Н. Расстройства речи в детском возрасте : в 4 т. Ленинград : Каргоиздат, 1940. Т. 4. С. 70-103.

Усанова О. Н. Особенности невербального интеллекта при недоразвитии речи: обучение и воспитание дошкольников с нарушениями реми. Москва : Просвещение, 1982. 142 с.

Филичева Т. Б., Чиркина Г. В. Устранение общего недоразвития речи у детей дошкольного возраста: практическое пособие. Москва : Айрис пресс, 2004. 204 с.

Цветкова Л.С. Мозг и интеллект: нарушение и восстановление интеллектуальной деятельности. Москва : Просвещение, 1995. $304 \mathrm{c.}$

Шаховская С. Н. Развитие словаря в системе работы при общем недоразвитии речи. Москва : Экономика, 1997.250 с.

Canon C. Implementing research practices. The high school journal. 2006. № 4. P. 8-13.

\section{REFERENCES}

Belova-David, R. A. (1973). Klinicheskie osobennosti detei doshkol'nogo vozrasta s tyazhelymi formami nedorazvitiya rechi [Clinical features of preschool children with severe forms of speech underdevelopment]. (Extended abstract of MedD dissertation). Moskva [in Russian].

Bekhterev, V. M. (1994). Izbrannye raboty po sotsial'noi psikhologii [Selected Works on Social Psychology]. Moskva: Nauka [in Russian].

Vygotskii , L. S. (1999). Pedagogicheskaya psikhologiya [Pedagogical psychology]. Moskva: Pedagogika-Press [in Russian].

Garkusha, Yu.F. (1983). Opyt razvitiya proizvol'nogo vnimaniya u detei s motornoi alaliei [Experience in the development of voluntary attention in children with motor alalia].Defektologiya [Defectology], 4, 23-24 [in Russian].

Grinshpun, B. M. (1988). Razvitie kommunikativnykh umenii u doshkol'nikov v protsesse logopedicheskoi raboty nad svyaznoi rech'yu [The development of communicative skills in preschoolers in the process of speech therapy work on coherent speech]. Defektologiya [Defectology], 3, 81-84 [in Russian].

Kovshikov, V. A. (2006). Ekspressivnaya alaliya i metody ee preodoleniya [Expressive alalia and methods for overcoming it]. SanktPeterburg: Karo [in Russian].

Kovshikov, V. A., \& El'kin, Yu. A. (1980). K voprosu myshleniya u detei s motornoi alaliei [On the issue of thinking in children with motor alalia]. Defektologiya [ Defectology], 2, 14-22 [in Russian].

Kol'tsova, M. M. (1973). Dvigatel'naya aktivnost' i razvitie funktsii mozga rebenka: rol' dvigatel'nogo analizatora $v$ formirovanii vysshei nervnoi deyatel'nosti rebenka [Motor activity and development of the brain functions of the child: the role of the motor analyzer in the formation of the higher nervous activity of the child]. Moskva: Pedagogika [in Russian].

Kornev, A. N. (2006). Osnovy logopatologii detskogo vozrasta: klinicheskie i psikhologicheskie aspekty [The basics of children's logopathology: clinical and psychological aspects]. Sankt-Peterburg: Rech' [in Russian].

Levina, R. E. (1977). Svoistva lichnosti i ovladenie rech'yu v norme i patologii [Personality traits and mastery of speech in norm and pathology]. Moskva: Akademiya [in Russian].

Luriya, A. R. (1975). Rech' i myshlenie: materialy k kursu lektsii po obshchei psikhologii [Speech and thinking: materials for a course of lectures on general psychology]. Moskva: MGU [in Russian].

Mastyukova, E. M. (1997). Lechebnaya pedagogika (rannii i doshkol'nyi vozrast): sovety pedagogam i roditelyam po podgotovke $k$ obucheniyu detei s osobymi problemami v razvitii [Therapeutic pedagogy (early and preschool age): advice for teachers and parents on preparing for teaching children with special developmental problems]. Moskva: Vlados [in Russian].

Orfinskaya, V. K. (2003). Printsipy postroeniya differentsirovannoi metodiki obucheniya alalikov na osnovanii lingvisticheskoi klassifikatsii form alalii. Logopediya [The principles of constructing a differentiated methodology for teaching alaliki on the basis of the linguistic classification of forms of alalia. Speech therapy]. Moskva: Vlados [in Russian].

Sobotovich, E. F. (2003). Rechevoe nedorazvitie u detei i puti ego korrektsii (deti s narusheniem intellekta i motornoi alaliei) [Speech underdevelopment in children and ways of its correction (children with impaired intelligence and motor alalia)].Moskva: Klassik stil' [in Russian].

Traugott, N. N. (1940). Rasstroistva rechi v detskom vozraste [Speech disorders in childhood] (T. 4, pp. 70-103). Leningrad: Kargoizdat [in Russian].

Usanova, O. N. (1982). Osobennosti neverbal'nogo intellekta pri nedorazvitii rechi: obuchenie $i$ vospitanie doshkol'nikov s narusheniyami remi [Features of non-verbal intelligence in speech underdevelopment: training and education of preschoolers with impaired remy]. Moskva: Prosveshchenie [in Russian].

Filicheva, T. B., \& Chirkina, G. V. (2004). Ustranenie obshchego nedorazvitiya rechi u detei doshkol'nogo vozrasta [Elimination of general underdevelopment of speech in preschool children]. Moskva: Airis press [in Russian].

Tsvetkova, L. S. (1995). Mozg i intellekt: narushenie i vosstanovlenie intellektual'noi deyatel'nosti [Brain and intelligence: violation and restoration of intellectual activity]. Moskva: Prosveshchenie [in Russian].

Shakhovskaya, S. N. (1997). Razvitie slovarya v sisteme raboty pri obshchem nedorazvitii rechi [The development of the dictionary in the system of work with a general underdevelopment of speech]. Moskva: Ekonomika [in Russian].

Canon, C. (2006). Implementing research practices. The high school journal, 4, 8-13.

\section{VALENTYNA DVIZHONA}

Place of work: Preshov, University

Country: Ukraine

Email:valen.tina79@ukr.net

CHARACTERISTICS OF MOTOR AND COGNITIVE DEVELOPMENT OF PRESCHOOLERS WHITH MOTOR ALALIA

During the presentation of the article the problem of motor and cognitive development of preschool children with motor alalia was highlighted, which has become a priority at the current stage of development of inclusive education in Ukraine and in the world. This is due to the increase in the number of children with various speech disorders that have a significant impact on the child's learning.

The article contains a detailed description of the defect structure in motor alalia, which is characterized by unevenness of verbal and nonverbal disorders, which makes the development of speech more complex, what kind of difficulties children with motor alalia overcome when acquiring basic skills in writing,learning spatial orientation. The article also focuses on various dysfunctions of self-organization that have a negative impact on the processes and outcomes of thinking. And, as a result - the need to focus on individualization of the learning process, taking into account the features of motor and cognitive development of a child with motor alalia.

Key words: ontogenesis; dysontogenesis; motor development; cognitive development; motor alalia. 